\title{
Paramoeba sp., an agent of amoebic gill disease of turbot Scophthalmus maximus
}

\author{
Iva Dyková ${ }^{1, *}$, Antonio Figueras ${ }^{2}$, Beatriz Novoa $^{2}$, Jacobo Fernandez Casal $^{3}$ \\ 'Institute of Parasitology, Academy of Sciences of the Czech Republic, Branišovská 31, CZ-370 05 České Budějovice, \\ Czech Republic \\ ${ }^{2}$ Concejo Superior de Investigaciones Cientificas, Instituto de Investigaciones Marinas, Eduardo Cabello 6, E-36208 Vigo, Spain \\ ${ }^{3}$ Insuina, Ardia 171, O Grove, E-36980 Pontevedra, Spain
}

\begin{abstract}
Amoebic gill disease of turbot Scophthalmus maximus L. assoclated with mortalities was repeatedly diagnosed at culture facilities in NW Spain. The angent was assigned to the genus Paramoeba Schaudin, 1896. Trophozoites found in the gill tissue as well as those cultured displayed most of the principal characteristics of $P$. pemaquidensis Page, 1970. The identity with $P$. pemaquidensis, known as an agent of gill diseases of salmonids, is yet to be assessed using non-morphological criteria.

KEY WORDS: Paramoeba. Gill infection Scophthalmus maximus - Mariculture
\end{abstract}

\section{INTRODUCTION}

Among the agents of amoebic gill diseases of fish, Paramoeba spp. seem to play the most important role. Mortalities related to Paramoeba spp. have occurred in Oncorhynchus kisutch reared in sea water in Washington and California, USA (Kent et al. 1988) and in Atlantic salmon Salmo salar from Tasmania, Australia (Roubal et al. 1989, Bryant et al. 1995, Howard \& Carson 1995), Ireland, France and Spain (Munday et al. 1990, Rodger \& McArdle 1996, Palmer et al. 1997). Using genus-specific polyclonal antisera, Howard \& Carson (1995) also validated the importance of Paramoeba species for $S$. salar by retrospective examination of gill sections from fishes affected between 1985 and 1991.

Despite a comprehensive effort, the identity of the species of amoebae causing gill diseases of salmonids (Daoust \& Ferguson 1985, Bleie et al. 1997, Noble et al. 1997) as well as fishes belonging to other families in diverse parts of the world remains uncertain. The urgent need for taxonomic studies in this field was stressed in 1995 by Bryant et al, one of the most

·E-mail: iva@paru.cas.cz advanced groups of researchers investigating gill diseases of salmonids. In the same year we reported turbot Scophthalmus maximus L as a new host endangered by amoebae in intensive cultures (Dyková et al. 1995). Amoebae were found to cause severe gill tissue damage in turbots at a grow-out facility in northwestern Galicia, Spain. Although the primary role of amoebae in the development of disease condition and occurrence of mortalities was clearly evidenced, the diagnostic features available in histological sections did not permit diagnosis of the agent.

The aim of this communication is to present what we have learned about the agent of amoebic gill disease of turbot from outbreaks which followed those described previously (Dyková et al. 1995).

\section{MATERIALS AND METHODS}

Fourteen grown turbots with an average weight of $2 \mathrm{~kg}$ were examined in December 1996 at the culture facility in NW Spain where mortalities occurred between October and December that year.

In addition to light microscopy of gill scrapings and histological examination of gills and visceral organs, gill samples were studied using transmission electron 
microscopy (TEM). Tissue samples were fixed in Davidson's fluid, embedded in Histoplast S (Serva) and stained with hematoxylin and eosin and with the Feulgen reaction for DNA. Small pieces of tissue sampled for TEM were fixed in cold, $0.1 \mathrm{M}$ cacodylatebuffered $2 \%$ osmium tetroxide and embedded in Mollenhauer's Epon (Poly/Bed 812)-Araldite (Dykstra 1993). For the ultrastructural study, a Jeol JEM 1010 electron microscope operating at $60 \mathrm{kV}$ was used.

In order to isolate amoebae from gill tissue, parts of gill arches (not examined by scraping) were placed on cerophyl-seawater (CS) and MY100S agars (Page 1983) in Petri dishes. The same types of agar seeded with autoclaved suspension of Pseudomonas sp. were used for subcultivation of strains and clones. Excised pieces of agar with trophozoites alld acompanying microorganisms (bacteria and flagellates) grown in the second passage were placed into CS and MY100S liquid media in cell culture flasks (Falcon).
The identification of the agent of turbot gill lesions was based on trophozoite morphology as observed in fresh mounts from gill tissues, in a $2 \mathrm{wk}$ old culture in CS and MY100S media, and in histological and ultrathin sections from affected gill tissue.

\section{RESULTS}

A new case of amoebic gill disease of turbot Scophthalmus maximus was diagnosed at the turbot farm Among the disease signs, behavioural alterations namely reduction of feeding activity and reverse posture (ventral side up), were observed in the infected stock. The onset of mortalities was in October; they occurred over an extended perind of time rup to December of the same year), with a rate of 5 to $20 \%$ in turbots weighing $500 \mathrm{~g}$. Fish in 20 out of 150 tanks were affected. The maximum/minimum water temper-

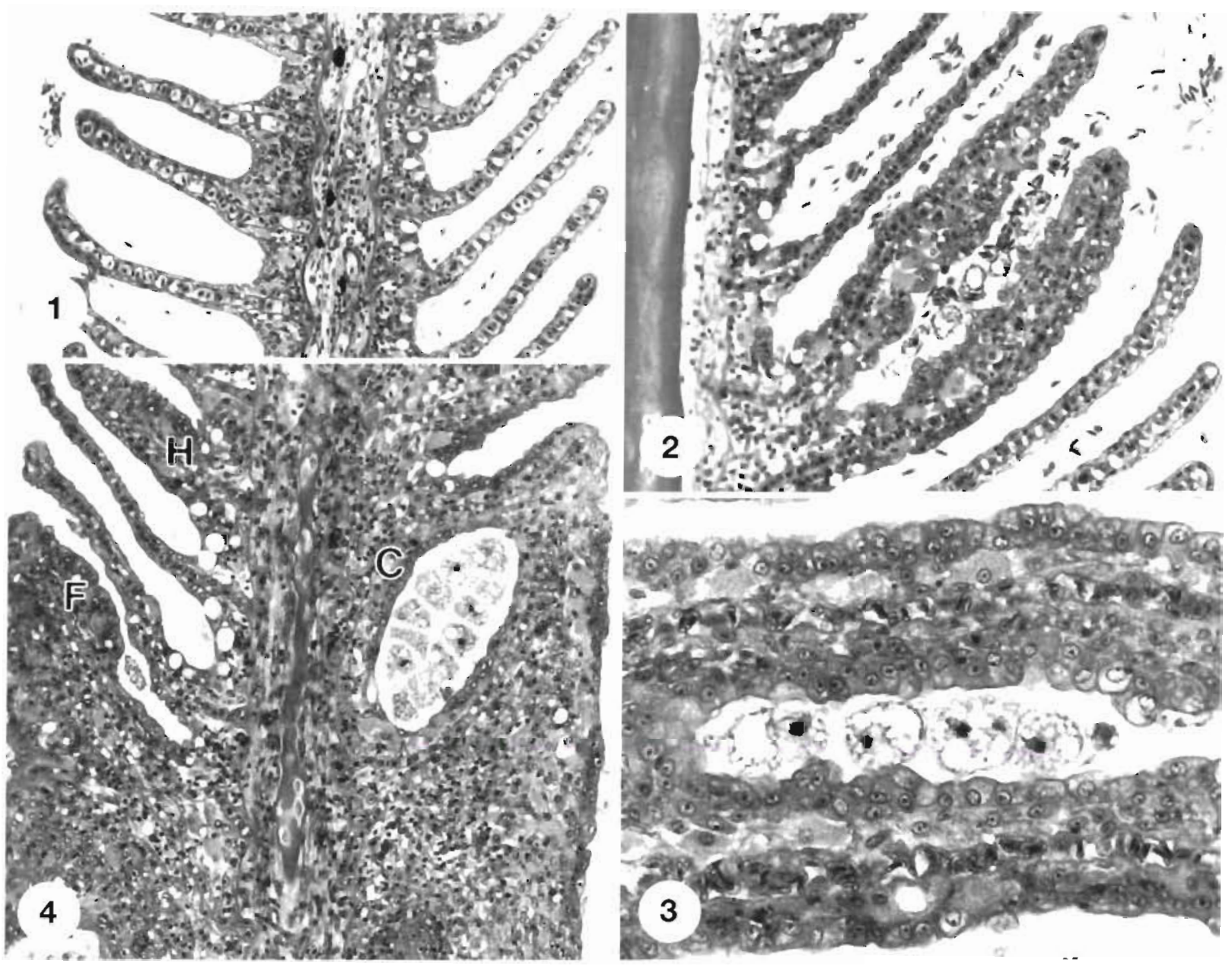

Figs. 1 to 4. Scophthalmus maximus. Fig. 1. Part of a healthy gill filament of turbot. HE, $\times 260$. Figs. 2 \& 3 . Two adjacent secondary lamellae hypertrophied due to accumulation of Paramoeba trophozoites in betweer. HE, $\times 260$ (Fig. 2) and $\times 530$ (Fig. 3 ) Fig. 4. Advanced stage of Paramoeba sp. infection. Part of the gill filament with hypertrophic (H) and fused (F) secondary lamellae and cavity (C) containing amoebae. HE, $\times 290$ 
ature in fish tanks was $18.8 / 14.5^{\circ} \mathrm{C}$ in October, $14 / 10^{\circ} \mathrm{C}$ in November and $14 / 9.1^{\circ} \mathrm{C}$ in December. The salinity was $22 \mathrm{ppt}$ throughout the study period. A formalin bath applied while waiting for examination results did not affect the course of the infection.

Gross examination of 14 turbots transferred from the affected farm to laboratory tanks revealed gill abnormalities in 4 out of the 14 specimens examined. The gills were covered with an excess of mucus, the gill filaments were clubbed, and some of them were shortened showing evidence of necrosis. The gill filaments in arches with irregular outline had an abnormal greyish peripheral coloration.

Giant trophozoites of amoebae observed in scrapings from gill filaments were most numerous in preparations from specimens with macroscopically visible lesions. The highest number of trophozoites per field of view determined selection of turbots for TEM sampling
Histological examination succeeded in revealing the presence of amoebae in the gill tissue of all the specimens in our assemblage. The appearance of an uninfected segment of a gill filament can be seen in Fig. 1. All the basic pathogenetic phases of amoebic gill disease revealed in the original detailed description (Dyková et al. 1995) were observed in a pronounced form this time. The accumulation of amoebae in the interlamellar spaces (Figs. $2 \& 3$ ) was accompanied by thickening of secondary lamellae due to hypertrophy and hyperplasia of epithelium (Fig. 3). Later, the lamellae fused (Fig. 4), channels and cavities formed and finally the lamellar structure of gill filaments disappeared completely (Fig. 4). Only one single bacterial embolus was detected in hundreds of examined histological sections, suggesting the insignificant role of bacteria in the development of gill disease.

Live amoebae in gill scrapings as well as those in histological sections had a foamy cytoplasm (Figs. 5
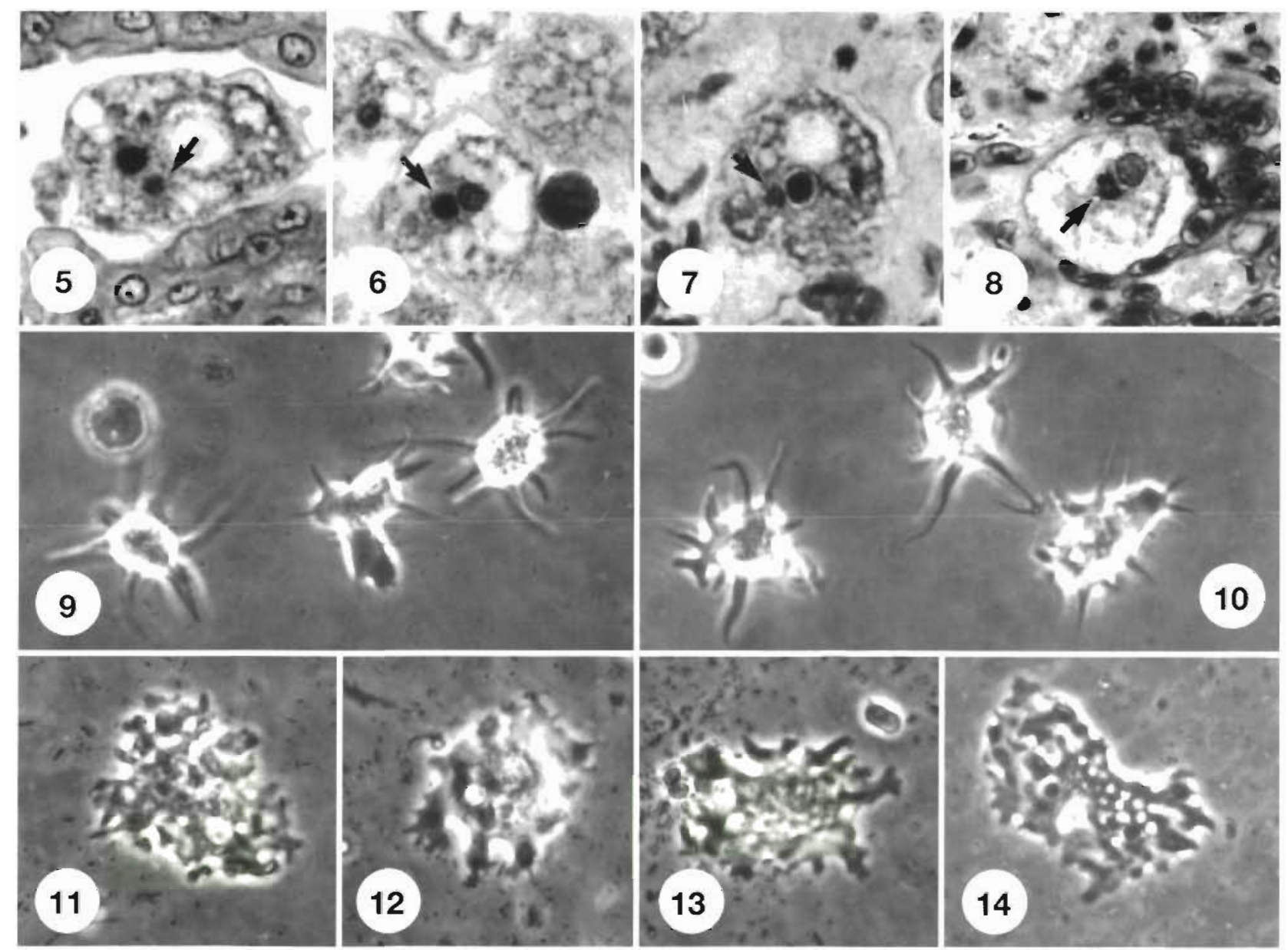

Figs. 5 to 14. Paramoeba sp. Figs. 5-8. Trophozoites in histological sections of affected gills. Arrows indicate parasomes. HE, $\times 700$. Figs. $9 \& 10$. Floating forms of Paramoeba trophozoites in liquid medium as observed using an inverted microscope with phase contrast, $\times 725$. Figs. 11-14. Trophozoites in liquid medium, attached to the bottom of culture flask. Inverted microscope with phase contrast, $\times 960$ 
to 8$)$, the diameter of which was 28 (21.8 to 40$) \mu \mathrm{m}$ $(n=30)$. When transferred onto CS agar, amoebae multiplied very slowly. The growth of agar plate cultures was suppressed by an overgrowth of accompanying bacterial flora, which also caused softening of the agar into which the trophozoites burrowed.

Trophozoites transferred from agar plates to culture flasks containing CS or MY100S medium also multiplied very slowly. The morphology of attached trophozoites as well as floating forms as observed using the inverted microscope with phase contrast (Figs. 9 to 14) corresponded to the description of Paramoeba spp. given by Page $(1970,1973)$. All the features stressed by Kent et al. (1988) as diagnostic for the genus Paramoeba were found in our strain isolated from turbot gilis. The presence of a pardsume (parañucleus) was visualized in histological (Figs. 5 to 8 ) as well as in ultrathin sections (Fig. 16). TEM revealed numerous vacuoles (Figs. $15 \& 18$ ) in the cytoplasm, a low number of mitochondria and a very low number of phagocy- tized bacteria. The cell surface was covered with a glycocalyx of fine filaments 275 to $300 \mathrm{~nm}$ in length (Fig. 17). Some of the trophozoites observed using the electron microscope gave the impression of moribund individuals. The possible influence of incorrect fixation could be excluded because of ultrastructural details discernible in adjacent host cells (Fig. 15, G).

In addition to Paramoeba sp., more than 20 strains of free-living amoebae were isolated from the gills of the same assemblage of 14 affected Scophthalmus maximus. Among them, 6 different species belonging to the genera Platyamoeba, Vannella, Flabellula and Gruberella have been identified thus far (to be published in a separate paper). Although evidently none of these was the agent of the described gill lesions of turbots, thcir pathogenic potential warrants further study. In contrast to the lesion-inducing Paramoeba, all the other amoebae which were associated with it in small numbers were easy to isolate and culture on agar plates seeded with Pseudomonas sp

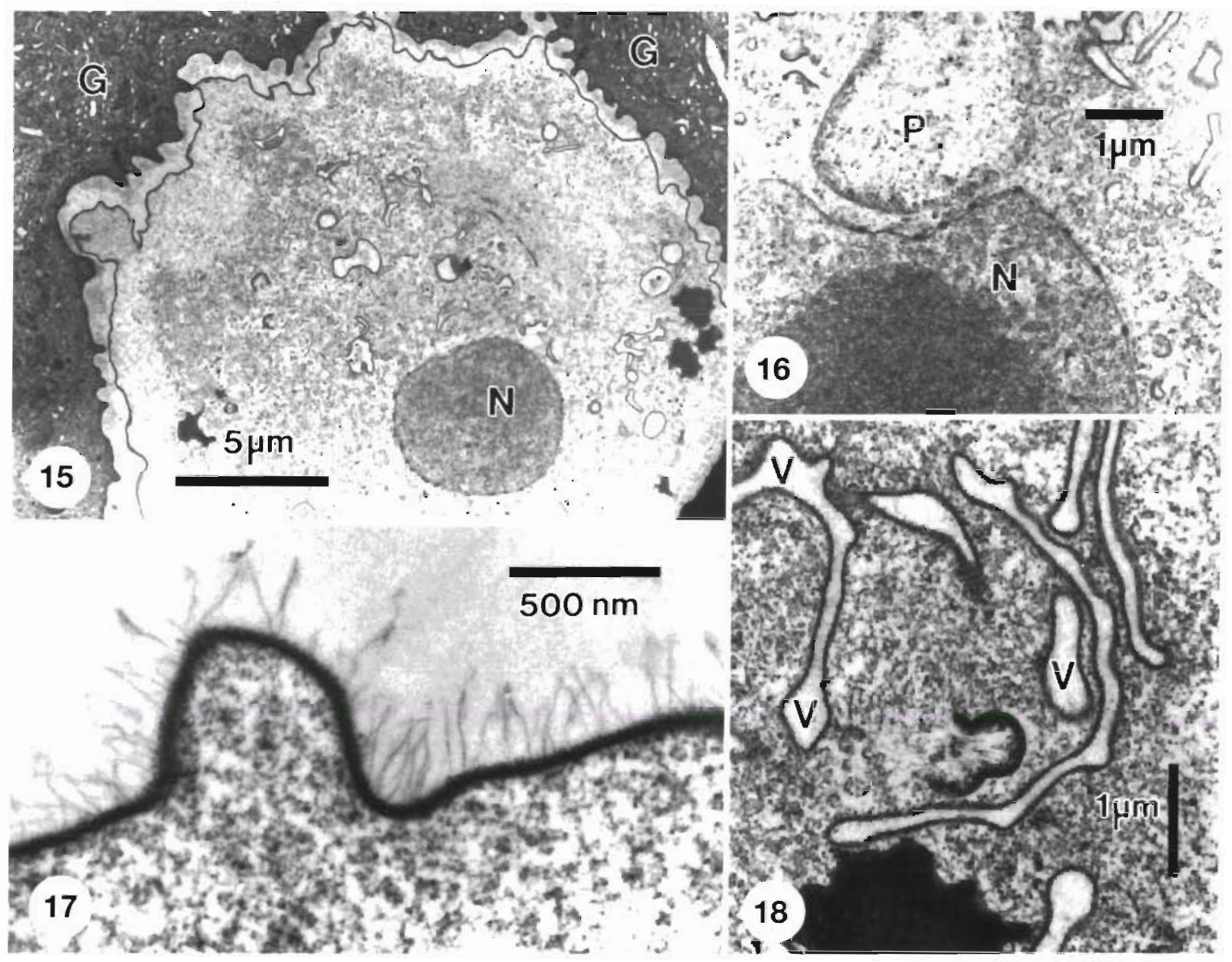

Figs. 15 to 18. Paramoeba sp. infecting Scophthalmus maximus. Fig. 15. Part of Paramoeba trophozoite (N: nucleus) surrounded by gill epithelium (G). Fig. 16. Parasome (P) next to nucleus (N) of Paramoeba trophozoite. Fig. 17. Glycocalyx differentiated in filaments. Fig. 18. Channels and vacuoles (V) giving foamy appearance to the cytoplasm of Paramoeba trophozoites 


\section{DISCUSSION}

The wide distribution and common occurrence of marine amoebae of the genus Paramoeba Schaudinn, 1896 were recognized by Page $(1970,1973)$ long after the original description of type species. In addition to the special interest paid to the morphology of Paramoeba because of the unique presence of the parasome apposed to the nucleus, the parasitic way of life discovered in some species focused even more attention on this group of marine amoebae. P. pemaquidensis Page, 1970 was described as a free-living species. Kent et al. (1988), who recognized this species as the agent of gill disease of Oncorhynchus kisutch, completed the light microscopical description by Page (1970) by describing the cell surface ultrastructure. We observed the same type of 'surface filaments' they described, i.e. the same type of arrangement of glycocalyx. Surprisingly enough, Kent et al. (1988) failed to find filamentous glycocalyx on the surface of trophozoites cultured on agar plates. Although we could not verify his finding on the absence of glycocalyx, because after a failure of the incubator we unfortunately lost the Paramoeba cultures, we have experience with more than 20 strains of marine amoebae which we know to maintain glycostyles when cultured on agar plates. We consider cellsurface structures of amoebae extremely important, especially in the genus Paramoeba because it includes species whose surfaces are covered with boat-shaped scales ( $P$, eilhardi Schaudinn, 1896) and with glycocalyx composed of tubular elements (Page 1983).

While measurements of trophozoites attached to the bottom of culture flasks fit in the range of locomotive forms of the 7 Paramoeba pemaquidensis strains described by Page $(1970,1973)$, as well as in the range given by Kent et al. (1988), the rounded (transitional) stages observed in gill tissue were larger. Their larger diameter can probably be explained by the phase of infection. We sampled material when the epizootic was already over, i.e. in addition to viable trophozoites there were also dystrophically changed ones.

Surprisingly low numbers of bacteria observed in the cytoplasm of trophozoites attached to the gill tissue supports the concept of the primary role of Paramoeba $\mathrm{sp}$. in the development of gill lesions.

Although most of the principal morphological features of Paramoeba sp. from turbot were identical with those of $P$. pemaquidensis, the agent of gill disease of salmonids, we would not like to declare the identity of both agents before non-morphological characteristics are also compared.
Acknowledgements. The fish used in this study were donated by the turbot producer Insuina, Ardia 171, O Grove, Pontevedra, Spain.

\section{LITERATURE CITED}

Bleie H, Levsen A, Dale OB, Hogstad IM, Nyberg K (1997) Mortality of parr and pre-transfer smolt of Atlantic salmon (Salmo salar) associated with amoeba-like organisms on the gills. Diseases of Fish and Shellfish, 8th Int Conf Eur Assoc Fish Pathol, Edinburgh, 14-19 September 1997 Abstract Book, P-060

Bryant MS, Lester RJG, Whittington RJ (1995) Immunogenicity of amoebic antigens in rainbow trout, Oncorhynchus mykiss (Walbaum). J Fish Dis 18:9-19

Daoust PY, Ferguson HW (1985) Nodular gill disease in rainbow trout, Salmo gairdneri Richardson. J Fish Dis 8: $511-522$

Dyková I, Figueras A, Novoa B (1995) Amoebic gill infection of turbot, Scophthalmus maximus. Folia Parasitol 42: 91-96

Dykstra MJ (1993) A manual of applied techniques for biological electron microscopy. Plerum Press, New York, p $22-49$

Howard TS, Carson J (1995) Amoebic gill disease of seacaged Atlantic salmon: disease, diagnosis and treatment. European Association of Fish Pathologists. Diseases of Fish and Shellfish, 7th Int Conf Palma de Mallorca, 10-15 September 1995. Abstract Book, p 7

Kent ML, Sawyer TK, Hedrick RP (1988) Paramoeba pemaquidensis (Sarcomastigophora, Paramoebidae) infestation of the gills of coho salmon Oncorhynchus kisutch reared in sea water. Dis Aquat Org 5:163-169

Munday BL, Foster C, Roubal FR, Lester R (1990) Paramoebic gill infection and associated pathology of Atlantic salmon, Salmo salar, and rainbow trout, Salmo galrdneri. in Tasmania. In: Perkins FO, Cheng TC (eds) Pathology in marine science. Academic Press, San Diego, CA, p $215-222$

Noble AC, Herman RL, Noga EJ, Bullock GL (1997) Recurrent amoebic gill infestation in rainbow trout cultured in a semiclosed water recirculation system. J Aquat Anim Health 9:64-69

Page FC (1970) Two new species of Paramoeba from Maine. J Protozool 17:421-427

Page FC (1973) Paramoeba: a common marine genus. Hydrobiologia 41:183-188

Page FC (1983) Marine Gymnamoebae. Institute of Terrestrial Ecology (NERC), Lavenham

Palmer R, Carson J, Ruttledge M, Drinan E, Wagner T (1997) Gill disease associated with Paramocba, in sea reared Atlantic salmon in Ireland. Bull Eur Ass Fish Pathol 17: $112-114$

Rodger HD, MCArdle JF (1996) An outbreak of amoebic gill disease in Ireland. Vet $\operatorname{Rec} 139: 348-349$

Roubal FR, Lester RJG, Foster CK (1989) Studies on cultured and gill-attached Paramoeba sp. (Gymnamoebae: Paramoebidae) and the cytopathology of paramoebic gill disease in Atlantic salmon, Salmo salar L., from Tasmania. $\mathrm{J}$ Fish Dis 12:481-493

Submitted: December 23, 1997; Accepted: March 11, 1998 proofs received from author(s): May 18, 1998 